\title{
Shaping future research agenda on sustainability research within the CARPE network
}

\section{Erlijn Eweg ${ }^{1}$, Martijn Rietbergen ${ }^{2}$}

${ }^{1,2}$ Research Center Healthy and Sustainable Living, University of Applied Science Utrecht, The Netherlands

\begin{abstract}
Within the involved Higher Education Institutes of the CARPE network, many research groups are working on sustainability related topics. However, the expertise of these research groups are not fully exploited if it comes to acquiring new opportunities for externally funded research projects. This proposed project aims at developing a research community among CARPE partners involved in sustainability research, to shape a joint future research agenda on sustainability research, and to explore how to get the most benefits out of our cooperation.
\end{abstract}

Keywords: Sustainability; cooperation; research; community (maximum 6).

\footnotetext{
1 erlijn.eweg@hu.nl

2 martijn.rietbergen@hu.nl
} 


\section{Introduction}

CARPE was founded in November 2011. A CARPE university conducts research and provides education that is demand-driven and which contributes to innovation of the professional practice; with strong links to small and medium enterprises (SMEs), large enterprises, the public sector and local and regional governments. Over the last years CARPE colleagues have been offered several opportunities to learn about mutual interests and expertise's (e.g. at CARPE conferences and workshops), leading to a consolidation of the consortium and having teachers, researchers and support staff feel closely linked with CARPE partners. The CARPE partners aimed to encourage cooperation in European research programs, jointly develop educational programmes and exchange students and staff and many times with success.

\section{CARPE and sustainability}

Since the beginning of the 21 st century the majority of the world population lives in urban areas. This urbanization poses important challenges for cities of the future: how do we solve the problems related to energy mobility and waste? And how can we solve that in a smart way, for example with the help of ICT? The future of human mankind depends to a great extent on whether we will be able to boost the sustainable development of cities. All CARPE university embrace the topic of sustainability in their own urban living environments. The main question that we like to explore is if our cooperation can be further strengthened (organized) aiming at developing integrated sustainable solutions for economic, social and environmental problems in urban areas in various European regions.

\subsection{The experience so far}

At the CARPE conferences, and as an outcome of the cooperation in the former IP (Intensive Programme) project ISA (International Sustainable Architecture), awareness was risen among the CARPE partners that an integral approach to realize sustainable cities is needed and that the best results can only be reached in tight cooperation with our stakeholders, the municipalities or local authorities or companies. Different disciplines have to work together to tackle the challenges, for example disciplines like Built Environment, Engineering, Urban Development, but also concerning Creative Engineering, Design, Economics, Socials, Community, Governance and Incubator Facilities. As follow up on ISA, in 2014 a strategic partnership was developed, the so called ESSENCE project, about European Sustainable solutions for Existing and New City Environments. The subject of ESSENCE was to develop sustainable solutions for existing and new city environments. Although the project ended in 2016, jointly developed learning material is still in use by various partners of this project. A 
minor programme on smart sustainable cities is yearly offered by HU Utrecht, with participation of teaching staff from Hamburg, Turku, Valencia and Manchester.

As a follow up of this cooperation, another Erasmus project was started, a Capacity Building project called SAUNAC, meaning: Sustainability Alliance of Urban Networks in Asian Cities. This Capacity Building project aimed to increase employability, skills for new business creation, active participation of young people in society and sense of initiative and (social) entrepreneurship especially concerning environmental awareness. Through opportunities for learning mobility and joint efforts from education to societal challenges the competences/skills regarding the contribution to society and environment were improved. Both projects did give answers to one key issue on the EU's agenda for change: "... a greater focus on investing in drivers for inclusive and sustainable economic growth..." "With the international dimension of education and training, we could promote diversity and intercultural awareness especially for sustainable urban areas.

Apart of the activities above, each CARPE university contributes to the subject of sustainability by preparing Open courses, based on their specific expertise and interest in the course topics (people, planet, profit, methods, and projects). Until know we have seen that the CARPE partners bring in expertise knowledge on the following specific competences, as shown below:

- HU: Social innovation, co-design, blended learning approaches, sustainable renovation, policy regulations, city design; healthy living effects of sustainability, energy systems;

- UPV: Building integrated modeling, materials integration, construction technology systems, and landscape design \& green infrastructure;

- HAW: Logistics and transport, smart grids, electric transport, ICT, climate adaptation;

- MMU: Future cities, Eco-innovation, business models for sustainable energy, facilitating entrepreneurial activities;

- TURKU: Water in the cities, energy in the cities, environment \& wellbeing in the city; circularity.

- Debrecen: Health in relation to pollution, water management, linguistics

\subsection{Bottlenecks}

In our cooperation we notice some bottlenecks that affect the success of our cooperation. First, we identified that in the cooperation nowadays, we often depend on actual calls for funding of our activities. And it might be that reacting on opportunities, is not always the best 
strategy to be successful. Second, we do not know whether these subjects /calls are in line with the strategic choices of each university. At the moment we cannot oversee whether these subjects do correspond only to the involvement of certain active research groups, or do they correspond with the specialism of the university? Third, cooperation has often not been formalized, and depends on good will of individuals. E.g. the minor Smart Sustainable Cities in the Netherlands has to be organized each year again, and depends on guest speakers from other CARPE universities, and the opportunities for student research projects abroad. Better knowledge of the specialisms of each other, better alignment of the research within the Carpe partners, could be an interesting approach to start with. As the rector from UPV explains "If we want to turn them [the proposals] into successful initiatives, we need to work together within support structures that benefit our projects and make them stand out in today's highly competitive environment ${ }^{\text {'ii }}$.

\section{The future challenge for CARPE}

Resuming, we can conclude that the development of integrated sustainable solutions for economic, social and environment challenges in urban areas is demanded. Over the last decades important geographical, demographical and environmental changes have taken place in the urban environment. The rate of urbanization increases rapidly, urban population is increasingly ageing and environmental pressures in especially urban areas are growing. The need for a transition towards more sustainable cities requires a reinforcement of academic programs that educate professionals able to develop viable solutions for smart sustainable cities. By our experiences we think that our knowledge and expertise on societal challenges will improve the quality of possible solutions with impact on regional societies, as a result of the cooperation between CARPE partners (universities) and national, regional and local government. The need for these solutions are underlined also by the European Commission iii. "Higher education is at the heart of Europe's ambition to become a smart, sustainable and inclusive economy: it plays a crucial role in individual and societal advancement; and, with its impact on innovation and research, it provides the highly skilled human capital that knowledge-based economies need to generate growth and prosperity."

\subsection{CARPE research}

In the context of urban-societal needs we have to form an integral approach to obtain sustainable cities, with involvement of national, regional and especially municipal governments, whose important role in setting a vision for sustainable cities was appointed already in Rio 20+ (art. 136 RIO 20+ decisions). The shared vision on sustainable cities between HEIs and authorities is essential for the cooperation on smart sustainable cities. The participating organizations can learn from each other's approaches and we have to learn to work better together on societal challenges in the new cultural environment with innovative 
approaches. Collaborative learning within CARPE on Smart Sustainable Cities can be left up to a next phase of development: building a community of research and practice, a system for peer feedback and preserving knowledge gained in projects. We like to explore 3 subjects with you during the conference in Valencia, October 2019, to resolve the former mentioned bottlenecks:

- Can the development of a community of practice and research, or even a joint research center on Smart Sustainable Cities be helpful to us?

- Is working on a joint future research agenda interesting to offer us more understanding of the research subjects and specialism of each CARPE partner? And in the case that we are able to make a start with a joint agenda, will this be helpful to make our impact more visible in Europe, or even more visible in European policy on applied research?

- And finally, can COST be an interesting call to realize this ideas, starting with urban -societal needs to obtain sustainable cities?

\subsection{Potential source of funding}

One potential source of funding might be the European Cooperation in Science \& Technology - COST ( $\underline{\text { www.cost.eu }}$ ). COST provides international research funding for researchers to set up their interdisciplinary research networks in Europe and beyond. COST provides funds for organizing meetings, training schools, short term scientific missions or other networking activities. Our suggestion for the cooperation in a COST project aims at developing a more intensive and structural cooperation of research communities among CARPE partners involved in sustainability research, to shape a joint future research agenda on sustainability research, and to acquire new funds effectively.

\section{References:}

i “Increasing the impact of EU Development Policy: An Agenda for change".

Communication from the Commission to the European Parliament, the Council, the European Economic and Social Committee and the Committee of the Regions, Brussels, 13.10.2011, COM(2011) 637 final

ii "Let's maintain strong links" - Carpe- a European network of Universities of Applied Sciences. 7.2018 page 3 .

iii "European Higher Education in the World". The commission to the European parliament - Brussels 11.7.2013 COM 499 final 